\title{
Local Self-Governance as an Institution Which Develops the Social Activism of a Population (a Sociological Analysis)
}

\author{
Konstantin Antipyev ${ }^{1}$ \\ ${ }^{1}$ Perm National University, Russian Federation \\ Correspondence: Konstantin Antipyev, Perm National University, Perm, Monastyrskaya str. 119-6. 614068. \\ E-mail: konstantin_antipjev@mail.ru
}

Received: July 2, 2013 Accepted: July 21, 2014 Online Published: September 29, 2014

doi:10.5539/ass.v10n19p85 URL: http://dx.doi.org/10.5539/ass.v10n19p85

\begin{abstract}
The growth in social activity of a population and the obvious necessity to enhance the population's participation in socio-economic transformations at the local level actualizes the problem of the formation of a culture of social activism. The solution requires the development of optimal governance practices by municipal authorities in order to ensure the sustainable growth of the social activity of citizens with regards to solving the problems of self-governance. This article analyzes the determinants of the development of different population groups' social activity in Russian municipalities. As a result of the research performed, explanatory models of possible, socially useful activity at the local level have been worked out. The criteria and indicators of social activity proposed in this paper contribute to a better understanding of the social potential of the local community in terms of the presence of possible participants conducting the socio-economic transformation in said local community.
\end{abstract}

Keywords: democratization, socio-economic transformations, social transformations, local government, civic participation, social activity, local community, governance, quality, criterion, indicator

\section{Introduction}

Governance is being developed in the constantly changing political and social context (Stoker, 1998; Jolly, 2002). A local self-governance (hereinafter referred to as LG) provides its community with the possibility of making independent decisions on local issues (Mohammadi et al., 2011). The LG is defined as the local governmental authority and the society influencing it. It is, above all, about working together, participating in various spheres of life and the relationship that exists between administrative authorities and community groups (Park, 2003). The successful engagement of citizens in the governing processes is associated with the ability of the local government to establish effective relationships with the various organized groups of civil society and to develop civic activity (Montiel \& Barten, 1999). Civic participation plays the most important role in effective management. Ashley and Roe (Ashley \& Roe, 1998) describe such participation by the local community in a spectrum - from passive to active participation. The latter is made up of the following principals: "knowledge of the general problem," "an interest in solving it," "public discussion" and "joint participation." (McCall, 2000; Mossberger, Tolbert, \& McNeal, 2008, p. 48) Citizens can work with the local government by participating in elections, influencing decisions made by the local authority (Verba, Scholzman, \& Brady, 1995), or by participating in volunteer activities and affairs of the local community (Zukin et al., 2006, p. 51).

The result of the formation of classical sociological thought was the emergence of an interpretation of social activity (hereinafter referred to as SA) that was structural-functional and based on the principals of social conflict resolution. The first theory, (Parsons, 1991; Merton, 1968) interprets SA as the main incentive for social development. In social conflict resolution SA is described as the source and the means of resolving social conflicts (Coser, 1956; Dahrendorf, 1998). Giddens defines SA as an understanding of the competence of its participants and associates it with the concept of routine. (Giddens, 1979)

In the modern sociological discourse, SA is associated with social subjectivity, (Bourdieu, 1993) the immediate ability of an individual to influence his own situation, and the social transformation of society (Andreeva and Holdobin, 2013). In existing studies which focus on the role of the state and local government, in particular in the development of SA in transitional societies and social activity itself (Anheier et al., 2000), the SA of a population is often considered only in the context of a "superficial" transformation (Bondarenko, 2008; Zhavoronkov, 2009; Galchenko, 2012, pp. 52-68), and in the social transformation of the population (Zolotukhin, 
2004). The population of a municipality (hereinafter referred to as MU) brings forth adaptation strategies, which issue in modernizing transformations (Zaslavskaya, 2002; Yadov, 2006; Tikhonova, 2011). The ability of a family or an individual to maintain a certain income level is considered to be an indicator of positive adaptation (Zolotukhin, 2004). Thus, by definition, social energy is directed towards the realization of individual social trajectories. As a result, there is a lack of progress to the next phase on the mesoscale of SA; the process of emergence of various strata and groups is not associated with an objective assessment by a person of his own potential impact on the socio-economic development.

The goal of SA in a population is to satisfy certain social needs and, in the process, engage in social changes which, together, can lead to a creation of favourable conditions for the realization of group and individual interests (Razvorotneva et al., 2008). In this context, the main purpose of governance at the municipal level is the quality development of SA in solving problems of the LG through the development of optimal governing practices.

This study is based on the analysis of literature dedicated to the subjects of local self-governance, the role of self-governance as an institution of civil society, issues of civic participation and SA and identifying criteria and indicators of SA. As such, the aim of this study is to offer the optimal direction for the LG to impact the state of SA and its qualitative and quantitative development.

The main question that arises in the course of the study of SA is the formation of criteria defining SA and the indicators that are used to form it. Determining the criteria and indicators of SA is imperative and helps define the characterizing components in the concept of SA quality (socially useful or, in some definitions, "constructive" SA) (Zadorin, 2011; Galchenko, 2012). The analysis, conducted by the author within the framework of this study, provides the conclusion that the main criteria for the study of SA at the local level are: 1) the attitude of population to SA, and 2) the population's understanding of the methods of implementation of SA as well as their willingness to act constructively to solve problems by choosing a particular institutional form of SA.

Changing the vector of SA in a local community is possible, not by following the classical idea of how much influence a population has on social development, but the extent to which the population believes it is able to influence processes occurring at the local level and to which extent it understands the need for this influence. When speaking of SA at the local level, with the goal of its qualitative development, it is important to verify the positions of the various social groups regarding the changes that affect their daily lives. This verification develops a system of real priorities. Hence the second aim of the study is empirical. The question the author aims to answer is to what extent, and how well, the existing governing practices of LG affect the SA and the development of SA in the population.

\section{Literature Review}

The prevalent attitude in sociological traditions towards the LG is that it is, logically, the most democratic form of governance, characterized by an active participation of its citizens and a close interaction between social and political structures (Achkasov, 1998; Maloney et al., 2000; Torjman \& Leviten-Reid, 2003; Gorica, etc., 2012). Modern theories often consider LG from the point of view of sociological theories and categories (Sharpe, 1970; Banner, 1998; Vavilina, 2000; Zaslavskaya, 2002). One of the directions of the study of LG is to consider LG from the point of view of the institutional and structural-functional approaches. The structure of LG institution is represented in the form of a set of certain components: the overall demand for LG, value-normative content of the functions of local government, legitimate forms of organization and entities of LG. The functions of (Merton, 1968) LG as a social institution are (including, but not limited to): the ability of individuals to demonstrate independence, initiative, energy, enterprise, provision of social justice, etc. (Fokin, 2003).

In the current perspective, local governance should be transparent, based on the principle of the widest and most effective public participation (Albalate, 2012). In order to increase the participation of citizens, local authorities should endeavour to adopt new forms of participation and strongly encourage the development of civil and social activity. One of the important challenges in the new millennium will be to find effective ways of attracting public attention to the formation of communities (Gibson et al., 2005).

Despite the fact that SA is being influenced by various factors, the critical factor for success is high-level management (UNICEF, 2008). According to Maloney et al. (2000), "administration of the territory affects the social capital, but, in turn, it is itself influenced by social capital". This approach develops Putnam's concept (Putnam, 2000), which states that if the local government can improve social capital, it can also contribute to the development of constructive (positive) SA. LG create the conditions under which SA develops and play a leading role in determining the level of impact that the local population has. This interaction will be effective in 
the absence of censorship, the presence of literacy and if the actors are able to effectively communicate (Harold, 2007).

"Trust Establishment" between the municipal government and the public is only possible if the local government creates adequate models (mechanisms) for community participation in governance. Trust forms the basis for an active interaction (Siisiäinen, 2000). The local government can use innovative governance techniques that will contribute to the development of SA (Gryudhoy, 2013). Ideally, a civil society, civic initiatives, and regulations for solving social problems should begin to form within the LG (Wojtowicz, 2013).

The state and level of SA of a population in solving the problems of an MU is the most important criterion for the successful functioning of local self-governance and the major indicator of the effectiveness of its enforcement by the local agencies (Pytkin \& Balandin, 2013).

According to Putnam, even in "modern" and "developed" countries, the features and the types of social relationships were the most important conditions for the effectiveness of local governance (Alatas, 2002). Thus, for the analysis and evaluation of a local government, it is necessary to define what is needed to develop the potential of SA, and to identify potential weaknesses and limitations in ongoing activities that strengthen said potential (UNDP, 2008).

The Constitution of the Russian Federation has documented the dual nature of local self-governance both as a public authority which provides self-management of local communities and an institution of civil society.

Notwithstanding some innovations in the system of local self-governance in 2010-2012, the situation at the local level in Russia globally is not undergoing any significant changes.

At the level of local self-governance there are two main trends: 1) searching for effective schemes of interaction between municipal authorities and civil society; 2) the absence of fundamental changes in terms of the sustainable development of SA.

Legal nihilism and the illiteracy of the population result in the possibility of interest manipulation. Municipal authorities rarely develop truly effective communication with the public (Romanov, 2008). The resources and capabilities of municipalities are not sufficient for the realization of the needs of the population. The revenues, being accumulated in the territories of the municipalities, do not cover the expenditures of local budgets (Filippenko, 2013).

The SA of citizens is still very low. This turns LG into an inefficient and non-independent institution. Important issues of the MU such as the destruction of the local environment and the merging of government and business cannot be solved with only the help of the local government. The decline in SA of citizens is often promoted by the local authorities, who are not interested in the problems of citizens. The spectrum of "interaction imitations" used by authorities and officials of local self-governance in their work is very wide (Zimin \& Vinyar, 2012).

In Russia the problem of compatibility of national norms and values with the objectives of socio-economic development is as high as ever. One of the key prerequisites for the successful implementation of modernization projects is the presence and localization of social groups in Russian society, as well as their ability to function as instigators of action. The middle class itself is still in its formative stage (Tikhonova, 2011).

The hopes of population are pinned on changes coming from above (Gorshkov et al., 2011). For 30 percent of Russians "there is an opportunity to influence the situation", "generally, life is going well" (Gorshkov et al., 2011), i.e. the material aspects of life are believed to be the most important aspects. Thus, SA does not exceed the micro-social level. The latter implies the non-inclusion of mechanisms of altruistic activity in a population's attitude to ongoing MU social and economic policy. The culture of the SA has not been formed yet. Volunteer movements, those which do not aspire to a higher social status, stand out as the movements with the highest potential (Diskin, 2011). In general, Russians interest in SA does not exceed eight percent (Gorshkov et al., 2011).

\section{Methods and Data}

Based on the theoretical analysis of literary and statistical sources, this section of the paper interprets the results of the applied research and offers an analysis of the main determinants of the SA of a population in a Russian MU and the development of SA in that population.

The main criteria of SA research are the questionnaire tools used to obtain empirical and analytical data on the following subjects: the attitude of the population in a MU to SA (based on the credibility of the institutional forms of SA), understanding ways to implement SA (life strategy), and the willingness of the population to act constructively to solve their own or local social problems through the selection of the proposed institutional 
forms of SA. Based on the indicated criteria of SA research, its empirical indicators were selected as the following: the presentation of SA as a social relationship, citizen participation, the sharing of a common set of values, the assessment of the necessity of SA, the level and institutional forms of SA, the level of public confidence in both forms, and both the positive and negative information which affects the SA.

For a full understanding of the forming factors of SA, both a quantitative method (questionnaire) and qualitative method (focused interview) were used.

The use of the questionnaire method is required because of the necessity of obtaining summary data on the actual state of the social activity of residents of municipalities as well as characteristics, values, expectations and attitudes of different social groups of the MU (Strauss and Corbin, 1990, Morse, 1994; Yadov, 2003). Primary information gathering was done by conducting a questionnaire at the residence of respondents. Participants were chosen at random.

The study was carried out in seven regions of the Russian Federation (Table 1).

The author used a multi-stage, stratified, regionalized method in the last stage of random sampling of the criteria: location, type of municipality, gender, age, social status. This helped generate the representative sample (in both urban and rural populations). The actual sample size of the survey was 1793 respondents. The general target population was permanent residents, of both the urban and rural areas of Russia, ages 20 and older, living in single family homes.

The focused interview allows for an understanding of the nature and mechanisms of the emerging social phenomena (Yadov, 2003; Krueger, 2002), helps develop guidelines and mechanisms for the local government's impact on public relations, and identifies specific resources of the LG that can affect the state of SA. Please see Table 1.

Table 1. Sample (by region), and the number of respondents in the course of the quantitative study

\begin{tabular}{cccc}
\hline $\begin{array}{c}\text { Subject of the Russian } \\
\text { Federation by region }\end{array}$ & $\begin{array}{c}\text { Population (voters), } \\
\text { in thousands of people* }\end{array}$ & Sample & $\begin{array}{c}\text { In \% of total } \\
\text { respondents }\end{array}$ \\
\hline Moscow region & 5577 & 270 & 11.2 \\
Kursk region & 960 & 320 & 13.5 \\
Vladimir region & 1202 & 201 & 9.3 \\
Novgorod region & 528 & 224 & 10.8 \\
Penza region & 1121 & 324 & 19.2 \\
Tyumen Region & 1052 & 311 & 14.3 \\
Amur Region & 648 & 146 & 21.7 \\
TOTAL: & & 1796 & 100 \\
\hline
\end{tabular}

* The Central Election Commission of the Russian Federation. http://www.cikrf.ru/izbiratel/quantity/quantity_ 010112.html.

The study of SA, as well as its determinants, was conducted by the means of expert interviews and focus groups.

Altogether, there were 11 focus groups conducted in the four regions of the Russian Federation: Moscow region, Kursk Oblast, Vladimir Oblast, Tyumen Oblast. An analysis of the results of the applied research was performed, focusing on the participants' age, gender and group of SA participation.

Using the criteria for the study of SA to highlight the participating groups, the criterion of public awareness of the activities, which would result in the transformation of the social environment, was used. Aiming for the objective participation in solving local problems, the groups were divided into three parts: the "actively engaged" - socially active respondents who regularly participate in solving social problems at the local level, "not engaged " - respondents, who are not socially active and are not engaged in solving social problems at the local level; and "sometimes engaged" - respondents, who are sometimes engaged in solving social problems at the local level.

Among other criteria for the analysis of the given results, is the age of the respondents (Hu et al., 2012). The authors identified three groups: 1) respondents aged from 20 to 38,2) respondents aged from 39 to 59 and 3) respondents aged 60 and older (Table 2) 
Table 2. Sampling characteristics of the participating groups

\begin{tabular}{cccccc}
\hline & \multicolumn{2}{c}{ Gender, \% } & \multirow{2}{*}{ 20-38 years } & \multirow{2}{*}{ 39-59 years } & \multirow{2}{*}{ 60 years and older } \\
& Male & Female & & & \\
\hline "Actively engaged" & 28.3 & 32.3 & 25.4 & 37.2 & 38.6 \\
"Not engaged" & 59.5 & 52.6 & 33.0 & 36.9 & 32.4 \\
"Sometimes engaged" & 12.2 & 15.1 & 41.6 & 25.9 & 29.0 \\
\hline
\end{tabular}

The level of education and income of the participating groups generally corresponded to their age and social group.

In the "not engaged" group, there are significantly more respondents with a higher level of education, and the group of the "engaged" respondents had education levels at the primary, secondary or special secondary education levels. The level of income per family member in the group of the "not engaged" is higher than in the group of the "engaged".

\section{Results}

In studying the nature of the concepts of SA in the LG, the author introduced the "semantic identification" indicator, which shows what SA at the local level means to the respondent.

Considering the entire sample, we can say that 26.7 per cent of all respondents could not verbalize their own "idea" of what an "objective SA" is; this included 26.3 of respondents in the "actively engaged" group. So, realizing their life strategies, many respondents did not correlate their activity with SA, which can be attributed to the low level of awareness of the possible institutional forms of SA.

Most of the respondents do not consider themselves to be effective participants at the local level. However, the understanding that one's activity can influence the situation in the MO has been already formed. Most residents (67.8 per cent) feel the need to take the initiative in solving local problems.

The analysis of the responses to the questions about participation in local government shows an existing gap between the actual level of the SA and the proclaimed position.

63.6 percent of respondents believe that their active life and work in local government is able to improve the overall situation in the MU (Figure 1). As a result the population actively engaged in solving local problems is dissatisfied with how local authorities carry out their functions.

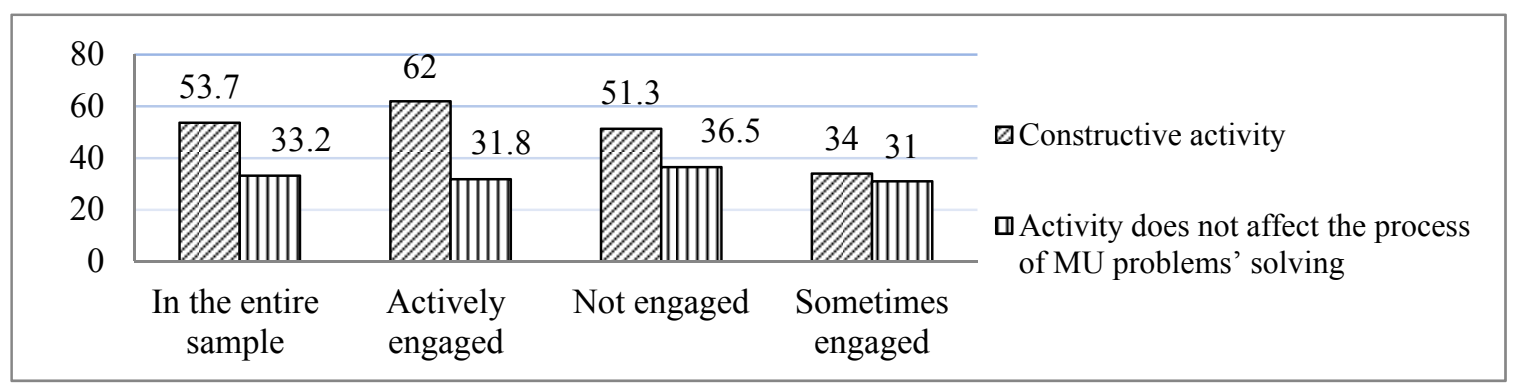

Figure 1. Respondents' assessment of the possibilities of addressing local issues by the means of social activity

(SA) in the MU, depending on personal participation in local government, \%

The important indicator of SA is the public confidence in the institutional forms of SA. The evaluation of the effectiveness of institutional forms of SA can identify which the forms in best engage residents. However, the results of the analysis showed that none of the forms of SA had the results that would enable them to be selected as a basis for cooperation. The residents consider joint activities to be the most effective forms of SA (34.7 percent).

As the analysis has shown, the most common forms of cooperation between local authorities and the public are the following: public hearings (82.7 percent), the personal reception of citizens by the Head of the MU (79.3 percent), meetings of MU executives with citizens (70.1 percent), the development and discussion of socio-economic developmental programs of the MU with the participation of citizens (58.5 percent). 
The respondents believe that the most useful forms of interaction between the local authorities and the population are meetings of MU executives with citizens (59.7 percent) and personal reception of citizens by the Head, City administration officers, and deputies of local councils (54.2 percent).

The effectiveness of the forms of SA, such as the filing of collective complaints, protests, and writing articles for local newspapers, do not have significant differences in the responses of respondents in all participating groups. The effectiveness of community councils is low. This can be attributed to the public distrust in these institutional forms of SA.

The people's willingness to act constructively in solving their group or local social problems through the selection of the proposed institutional forms of SA is especially important. The research has not shown significant differences in the participating groups and age groups, however, if we consider the forms of SA, the two patterns can be identified (Table 3): 1) the higher the amount of personal resources expected to be spent on activities under this form of SA, the fewer respondents are willing to pursue the issue, and 2) in all forms of SA where personal presence is necessary, respondents who do not participate in local decision-making are less willing to provide support to resolve an issue.

Table 3. Distribution of the respondents' answers to the question of their willingness to act constructively in solving their own group or local social problems by the criterion of group participation, $\%$

\begin{tabular}{ccccc}
\hline Possible answer & In the entire sample & Actively engaged & Not engaged & Sometimes engaged \\
\hline Sign a petition & 63.7 & 64.8 & 61.5 & 63.9 \\
Participate in public hearings & 51.2 & 51.7 & 43.9 & 49.4 \\
Meet with the Head of the MU & 14.4 & 23.6 & 15.9 & 21.4 \\
Provide financial assistance & 15.6 & 17.1 & 10.4 & 18.3 \\
Participate in volunteer activities & 21.1 & 19.9 & 19.1 & 22.3 \\
Unable to choose an answer & 5.2 & 5.6 & 5.0 & 4.9 \\
\hline
\end{tabular}

*There the possibility of choosing more than one answer was provided.

In the various forms of SA there are significant differences in the data gathered from participating groups. It should be recalled that the inclusion of a respondent in any of the groups, was carried out on the basis of the public awareness of the activities which result in the transformation of the social environment. Therefore, in the group of respondents who are "actively engaged" in solving local problems, there are respondents who have not been active during the last year. In the group "not engaged", part of the respondents participated in forms of self-government, but did not see it as being part of SA. This can be explained by the fact that the SA of these citizens is determined by the administrative actions of local authorities and the citizens' employers.

Respondents, who have participated in the various forms of SA, rated their effectiveness as positive (43.5 percent) or satisfactory (32.6 percent) in addressing local issues. However, there was a high percentage of respondents who found it difficult to assess the effectiveness of their actions (18.5 percent). 5.4 percent of respondents rated their effectiveness negatively.

This demonstrates the need for the promotion of positive results of the various forms of SA; that is, promoting how certain residents view their own performance, which may contribute to general positive perceptions of SA. In addition, the sense of inner satisfaction resulting from their work will cause socially active residents to continue being active.

Most of the respondents do not believe they have the ability to influence the decisions of municipal authorities. The "actively engaged" group assesses its ability to influence at a higher level than those respondents who are "not engaged." Consequently they are sometimes engaged in local decision-making (27.8, 13.1 and 20.7 percent, respectively). We attribute this to a positive experience from cooperation with the authorities, however, this level is quite low: it does not constitute even a third of the respondents in this group. Thus, this proves that the basis of the low level of confidence in the municipal authorities and the election of their officers are the objective assessments by the residents of the results of their performance.

When asked for the reasons that prevent the realization of structural SA, the answers of the "not engaged" and "sometimes engaged" respondents, were gathered.

The analysis showed that the main reasons which prevented the creation of a constructive SA include: passivity and dependency of citizens on the government (21.0 per cent), lack of administrative tools and capabilities to 
support citizens' initiatives (8.96 percent), the lack of a legal culture, illiteracy and lack of citizen awareness (4.20 percent), weak resource base of non-governmental organizations (3.18 percent), distrust of authority on the part of the population ( 2.96 per cent), poor development of civil society at the local level, the lack of leaders and high-grade non-governmental organizations ( 2.52 percent), and problems in the housing sector - specifically the complicated relationships between partnerships of housing owners and managing companies (1.76 percent).

The study of positive prerequisites for the development of SA was performed for the entire sample as a whole (Table 4).

Table 4. Distribution of answers to the question of the conditions, that can increase the structural SA in the MU, \%

\begin{tabular}{lcccc}
\hline Possible answers & $\begin{array}{c}\text { In the entire } \\
\text { sample }\end{array}$ & $\begin{array}{c}\text { Actively } \\
\text { engaged }\end{array}$ & $\begin{array}{c}\text { Not } \\
\text { engaged }\end{array}$ & $\begin{array}{c}\text { Sometimes } \\
\text { engaged }\end{array}$ \\
\hline High performance of activities & 33.1 & 33.6 & 27.7 & 30.3 \\
Solution of personal problems & 17.6 & 18.9 & 14.7 & 16.4 \\
$\begin{array}{l}\text { Realization of activities' utility and approval on the part } \\
\text { of the majority of residents }\end{array}$ & 16.7 & 17.8 & 14.1 & 15.1 \\
Opportunity to earn & 15.1 & 14.7 & 13.1 & 14.6 \\
Opportunity to influence local politics & 9.7 & 7.9 & 12.6 & 7.5 \\
Unable to choose an answer & 7.8 & 7.1 & 17.8 & 16.1 \\
Total & 100 & 100 & 100 & 100 \\
\hline
\end{tabular}

The table does not include such assumptions as "the awareness of participation in the life of the city as an element of democracy", "the desire to carry out the project by joint efforts", "protest", "pressure from the authorities," "psychological sanctions from the neighbours or colleagues," as they have a significance level of less than 10 percent.

As can be seen from Table 4, the main prerequisite for the development of SA of residents, regardless of the participating groups, is the guarantee of a positive result (33.1\%). For the group of "actively engaged " the most important incentives were the possibility of solving personal problems through a collective effort $(18.9,14.7$ and 16.4 percent, respectively) and an awareness of the usefulness of their activities and the approval of these activities by the majority of residents (17.8, 14.1 and 15.1 percent, respectively). This highlights the need for a social and psychological adjustment of the process of engaging residents in SA.

The basis of the analysis of characteristics of potential actors in the socio- economic transformation of the population of the MU should be, firstly, the selection of previously existing types of normative-value systems, not just the analysis of the various elements which create the views and values of the people, because in the various systems of relations and cultural traditions the same view, from the point of view of wording, may hide in itself different meanings and may be an indicator of different values.

Respondents of the "actively engaged" group have a number of prerequisites for active involvement in the various forms of SA. This group mainly consists of women, whose value system is oriented towards the family and ensuring the family well-being, including that of the economic kind. Therefore, the SA of this part of respondents largely depends on the local authority realizing the social function of this part of the population. Focusing on family values is consistent with an awareness of the necessity of exercising one's legitimate rights and freedoms, as well as building a career. If these qualities are not being fully realized at work or at home, they can become the basis for inclusion in SA at the level within which the living environment is formed.

Different groups have different perceptions about the "key idea" of the MU (Table 5).

However, the differences are very slight. In addition, it is possible to speak about a certain "frame" of basic values and the life strategies chosen, which leads to the conclusion that the value system of the MU residents is stable, but that the attitude of the population towards economic policy does not incorporate mechanisms of innovative activity in it. 
Table 5. Distribution of answers to the question about the "key idea" of SA, \%

\begin{tabular}{lccccc}
\hline \multirow{2}{*}{ Possible answers } & \multicolumn{2}{c}{ Male \% } & $20-38$ & $39-59$ & 60 years \\
& Male & Female & years & years & and older \\
\hline Equality of all before the law, respect for human and civil rights & 28.3 & 32.3 & 19.6 & 25.6 & 21.3 \\
Combating corruption & 22.5 & 20.0 & 25.2 & 28.5 & 30.1 \\
Providing social justice & 12.2 & 15.1 & 19.0 & 10.1 & 18.9 \\
Innovative development & 8.0 & 6.4 & & & \\
Revival of Russian values and traditions & 7.9 & 6.2 & & & \\
Development of free enterprise & 4.3 & 3.4 & & & \\
Unable to choose an answer & 16.8 & 16.6 & & & \\
Total & 100 & 100 & & & \\
\hline
\end{tabular}

It appears that the institutional forms of the SA at the local level should include greater opportunities for residents to be socially active in their $\mathrm{MU}$, in order to enhance socio-economic changes.

There is no possibility of radical changes in the lives of the majority of the respondents, yet. Among the population the concepts of dependence caused by external factors which they can't influence, are dominating (Table 6).

Table 6. The specifics of value orientations in groups, $\%$

\begin{tabular}{|c|c|c|c|}
\hline Possible answers & $\begin{array}{l}20-38 \\
\text { years }\end{array}$ & $\begin{array}{l}39-59 \\
\text { years }\end{array}$ & $\begin{array}{l}60 \text { years } \\
\text { and older }\end{array}$ \\
\hline My financial situation at present and in the future depends first of all on me & 53.3 & 42.5 & 22.5 \\
\hline Little depends on me - the economic situation in the country determines everything & 45.2 & 57.5 & 78.9 \\
\hline $\begin{array}{l}\text { Changes in Russian society should be carried out "from above", and the municipal } \\
\text { authorities should monitor their implementation }\end{array}$ & 54.6 & 65.3 & 63.4 \\
\hline $\begin{array}{l}\text { Changes should be carried out from the "bottom", relying on the initiative of } \\
\text { people, healthy forces within society, not on power }\end{array}$ & 34.8 & 34.5 & 25.6 \\
\hline In the affairs of the country much depends on ordinary citizens & 22.9 & 19.5 & 12.4 \\
\hline $\begin{array}{l}\text { In the affairs of the country nothing depends on ordinary citizens, it all depends on } \\
\text { the leaders and politicians }\end{array}$ & 77.3 & 80.5 & 73.9 \\
\hline
\end{tabular}

The majority of the respondents are not confident in the fact that their financial situation is associated with themselves and is not dependant on external factors. When looking at the awareness of different age groups of Russians, specifically at the participation in changing the situation in the MU, it should be noted that even the respondents under the age of 39 are sure that the municipal authorities are responsible for their success, as they do not believe that the existing institutional framework will enable them to effectively influence any reforms.

\section{Discussion and Conclusions}

The study found that, at present, the existing management practices of local governments in the implementation and development of SA in their population are not effective.

In order to improve the effectiveness of governance practices, the integrated view of SA at the level of MU must be generated. This is possible only providing that the major characteristics of SA, that is the criteria and indicators which allow the exploration of the SA in the population of a MU, are understood and can be used as the basis for the analysis and monitoring of SA at the level of MU, as well as to evaluate the performance of local governmental authorities with regards to the formation and development of SA. The main criteria of SA research at the local level, proposed by the author, are: the attitude of the municipal population to SA, public awareness of the ways it can be implemented and the willingness to act constructively to solve their group or general social problems by choosing a particular institutional form of SA. This approach to SA research, as 
shown in the analysis conducted, in contrast to the existing ones, contributes to a better understanding of the social potential of the local community in terms of the presence in it of the possible participants in the socio-economic transformation.

Formation of SA as a social relation at the local level requires an institutional design and regulations on the proper behaviour of participants in the social partnership. At this stage of the federal legislation development, the most appropriate action would be to further develop and allocate recourses to the most effective and legislated forms of self-government, which will provide for the real possibility of self-realization and self-organization of the MU through various forms of social participation in solving local issues. This allows the creation of obligatory conditions to further develop the constructive SA at the local level.

Changing the vector of SA in a local community is possible. Being guided by the results of sociological research dedicated to identifying the hierarchy of interests and the normative value orientations of the local community, the degree of public confidence in its ability to effectively influence the legislative processes occurring at the local level, and the willingness of the population to be an effective actor in local social and political processes will bring about that change. The basis of the analysis of the characteristics of potential participants in the socio-economic transformation in the population of a MU should be the selection of previously existing types of normative-value systems, and not just the analysis of the various elements which create the views and values of the people. The understanding of SA as a social relationship should be used as the empirical indicator to monitor the assessment of the necessity for SA, the institutional forms of SA, and the level of public confidence in these forms of SA, that is, both the positive and negative reactions that will affect the SA of a population.

The growth of socially useful SA in terms of socio-economic transformation requires the development and implementation of explanatory models in the governance of the MU. As a model, the following can be mentioned: institutionalized norms of modern secular morality, the culture of social behaviour in an MU, based on constructive SA; activities for the development of the creativity of the residents of a MU and funded by means of a special MU investment fund: development campaigns, promoting SA in the form of competitions for social initiatives, self-organization, partnership projects of the local businesses and citizens, activities to raise the profile of various forms of SA, which would be executed by officers working at specially established position of social manager, participation in programs of "civic education," volunteer projects, charity, social networks and professional associations, taking part in socially significant projects at the local level (within the NGO grants and individual projects), etc.

\section{References}

Achkasov, V. (1998). The experience of local authorities in the West. Law, 4, 43-48.

Alatas, V., Pritchett, L., \& Wetterberg, A. (2002). Voice Lessons: Local Government Organizations, Social Organizations, and the Quality of Local Governance. World Bank Policy Research Working Paper, 2981.

Albalate, D. (2012). The Institutional, Economic and Social Determinants of Local Government Transparency. Institut de Recerca en Economia Aplicada Regional i Pública. Research Institute of Applied Economics. Working Paper, 10.

Andreeva, M. A., \& Holdobin, D. V. (2013). The possibilities of education in the formation of the social activity of the individual student as a citizen and a patriot. Last number, 5(154), 9-13.

Anheier, H., Priller, E., \& Zimmer, A. (2000). Civil society in transition: The East German third sector ten years after unification Civil Society. Working Paper 15.

Ashley, C., \& Roe, D. (1998). Enhancing community involvement in wildlife tourism: Issues and challenges. IIED Wildlife and Development Series, No. 11. London: International Institute for Environment Development.

Banner, G. (1998). Von der Ordnungskommune zur Dienstleistungs- und Bürgerkommune. Der Bürger im Staat, 4, 179-186.

Bondarenko, S. (2008). The formation and development of social activism in the local government of a typical medium-sized city.

Bourdieu, P. (1993). Social Policy: Per. with Fr. / Comp., total. Ed. and foreword. N.A.Shmatko. M.: Socio-Logos.

Coser, L. (1956). The Functions of Social Conflict. New York: The Free Press.

Dahrendorf, R. (1988). The Modern Social Conflict: An Essay on the Politics of Liberty. L.: Weidenfeid \& 
Nicolson.

Diskin, I. (2011). Russia, which is possible. M. Lawyer.

Filipenko, A. (2013). The development strategy of municipal budgets. Federal Directory. Regions of Russia.

Fokin A. (2003). Formation of municipal government as a social institution in reforming Russia.

Galchenko, B. (2011). Current aspects of the sociological analysis of the problem of social activism at the local level, Quality of life as a criterion for social policy and management efficiency: The collection of papers and articles Under the general edition of V.I. Patrusheva. Moscow: OOO "Publishing Prospect".

Gibson, P. D., Lacy, D. P., \& Dougherty, M. J. (2005). Improving Performance and Accountability in Local Government with Citizen Participation. The Innovation Journal: The Public Sector Innovation Journal, 10(1), 1-12.

Giddens, A. (1979). Central problems in Social Theory: Action, Structure and Contradiction in Social Analysis. London: Macmillan.

Gorica, K., Kripa, D., \& Zenelaj, E. (2012). The Role of Local Government in Sustainable Development. ECONOMICA, 8(2), 139-155.

Gorshkov, K., Krumm, P., \& Tikhonov, H. (2010). Is Russian society toward modernization? Moscow: Publishing House of the whole world.

Grydehøj, A. (2013). Challenges to Local Government Innovation: Legal and Institutional Impediments to the Exercise of Innovative Economic Development Policy by Subnational Jurisdictions. European Journal of Spatial Development. Refereed article № 50.

Harold, D. (2007). The structure and function of communication in society. Lasswell İletişim kuram ve araştırma dergisi, 24, 215-228.

Hu, Y., Lei, X., Smith, J. P., \& Zhao, Y. (2012). Effects of Social Activities on Cognitive Functions. Evidence from CHARLS. IZA DP No. 7536. Forschungsinstitut zur Zukunft der Arbeit Institute for the Study of Labor.

Jolly, R. (2002). The history of development policy. In C. Kirkpatrick (Ed.), Handbook on Development Policy and Management. Cheltenham: Edward Elgar Publishing Limited. http://dx.doi.org/10.4337/97817819 50494.00009

Krueger, R. (2002). Designing and Conducting Focus Group Interviews. St. Paul: University of Minnesota.

Lowndes, V., \& Wilson, D. (2001). Social capital and local governance: Exploring the institutional design variable. Political Studies, 49, 629-647. http://dx.doi.org/10.1111/1467-9248.00334

Maloney, W., Smith, G., \& Stoker, G. (2000). Social capital and urban governance: Adding a more contextualized 'Top-down' Perspective. Political Studies, 48(4), 802-820. http://dx.doi.org/10.1111/1467 $-9248.00284$

McCall, L. (2000).Social Capital, Civic Engagement, and Civic Literacy: Reviewing, Refining, and Defining the Concepts. Public Performance \& Management Review, 25(4), 440-445. http://dx.doi.org/10.2307/3381139

Merton, R. (1968). Social Theory and Social Structure. New York: The Free Press.

Mohammadi, S., Norazizan, S., \& Shahvandi, A. (2011). Civic Engagement, Citizen Participation and Quality of Governance in Iran. J Hum Ecol, 36(3), 211-216.

Montiel, R., \& Barten, F. (1999). Urban governance and health development in Leon. Nicaragua. Environment and Urbanization, 11(1), 11-26.

Morse, J. (1994). Critical Issues in Qualitative Research Methods. Thousand Oaks, CA: SAGE Publications.

Mossberger, K., Tolbert, C. G., \& McNeal, S. (2008). Digital citizenship: The internet, society, and participation. MIT Press.

Park, W. (2003). International Understanding of Local Governance and the Present Conditions and Problems of Local Governance in Busan. Department of Public Administration, Silla University.

Parsons, T. (1991). The social system. London: Routledge, Taylor \& Francis Group.

Putnam, D. (2000). Bowling Alone: The Collapse and Revival of American Community. New York: Simon and Schuster, 2000. 
Pytkin, A., \& Balandin A. (2013). The development of local government in the rural municipalities of the Perm region. Bulletin of Udmurt University. Economics and Law, 1, 50-54.

Razvorotneva, C., et al. (2008). The conditions of increase of social activity of citizens in solving local problems. Analytical report on the quantitative and qualitative research. All-Russian Council of Local Authorities. M.

Romanov, P. (2008). Quality Evaluation in Social Services: Challenges for New Public Management in Russia. In G. Peters (Ed.), Mixes, Matches, and Mistakes. New Public Management in Russia and the Former Soviet Republics. Budapest: Open Society Institute, OSI/LGI: 9-53.

Sharpe, L. J. (1970). Theories and values of local government. Political Studies, 8(2), 153-174. http://dx.doi.org/ 10.1111/j.1467-9248.1970.tb00867.x

Siisiäinen, M. (2000). Two Concepts of Social Capital: Bourdieu vs. Putnam. Paper presented at ISTR Fourth International Conference «The Third Sector: For What and for Whom?». Trinity College, Dublin, Ireland.

Sinning, H. (2005/2006). Citizen-oriented local government and concepts of participation. JUC Journal of Social Work Theory and Practice, 12.

Stewart, D. (1990). Focus Groups. Theory and Practice. Applied Social Research Methods series, 20. Newbury Park: SAGE Publications.

Stoker, G. (1998). Creating a local govern for a post-Fordist society: The Thatcherite project. In J. Stewart (Ed.), The Future of Local Government. London: Macmillan.

Strauss, A., \& Corbin, J. (1990). Basic of Qualitative Research. Grounded Theory Procedures and Techniques. Newbury Park: SAGE Publications.

Tikhonova, H. (2011). Actors Russian modernization in the perception of the population and in reality. Bulletin of the Institute of Sociology, 3, 120-140.

Torjman, S., \& Leviten-Reid, E. (2003). The Social Role of Local Government. Caledon Institute of Social Policy.

Touraine, A. (1998). The Return of the man of action. Scientific World.

UNDP Oslo Governance Centre. (2009). A Users' Guide to Measuring Local Governance.

UNICEF EAPRO. (2008). Young People's Civic Engagement in East Asia and the Pacific. Bangkok.

Vavilina, H. (2000). Poverty in Russia as a social phenomenon and a social problem: Sociological Aspects.

Verba, S., Scholzman, L. K., \& Brady, H. E. (1995). Voice and equality: Civic voluntarism in American politics. Cambridge, Mass: Harvard University Press.

Wojtowicz. (2013). Modernization of the legal regulation of local self-government: Issues, Theory and Practice. Bulletin of Udmurt University. Economics and Law, 3, 128-131.

Yadov, V. (2003). Strategy for the survey. Description, explanation, understanding of social reality.

Yadov, V. (2006). Problems of Russian transformation. St. Petersburg: Publishing House SPbGUP .

Zadorin, I. (2011). Strategy - 2020. The expert group number 16: The development of social institutions. Support and encourage constructive social activity - subtle human capital management. 25.10.2011, version 3 .

Zaslavskaya, T. (2002). Societal transformation of Russian society: Activity-structural concept. M: Business.

Zimin, M., \& Vinyar, B. (2012). Simulation in the municipal administration. Modern problems of science and education, 6. Retrieved from http://www.science-education.ru/106-7753

Zolotukhin, A. (2004). Manifestations of social activism at the local level: Materials for the course "Local government as an object of social -psychological research".

Zukin, C., Keeter, S., Andolina, M., Jenkins, K., \& Carpini, M. (2006). A new engagement? Oxford: Oxford University Press. http://dx.doi.org/10.1093/acprof:oso/9780195183177.001.0001

\section{Copyrights}

Copyright for this article is retained by the author(s), with first publication rights granted to the journal.

This is an open-access article distributed under the terms and conditions of the Creative Commons Attribution license (http://creativecommons.org/licenses/by/3.0/). 